University of Nebraska - Lincoln

DigitalCommons@University of Nebraska - Lincoln

Papers in Plant Pathology

Plant Pathology Department

2012

\title{
Assessing genetic diversity in the web blight pathogen Thanatephorus cucumeris (anamorph = Rhizoctonia solani) subgroups AG-1-IE and AG-1-IF with molecular markers
}

N. González

University of Nebraska-Lincoln

James R. Steadman

University of Nebraska-Lincoln, jsteadman1@unl.edu

Robert Higgins

University of Nebraska-Lincoln, rhiggins2@unl.edu

Kent M. Eskridge

University of Nebraska-Lincoln, keskridge1@unl.edu

Follow this and additional works at: http://digitalcommons.unl.edu/plantpathpapers

Part of the Other Plant Sciences Commons, Plant Biology Commons, and the Plant Pathology Commons

González, N.; Steadman, James R.; Higgins, Robert; and Eskridge, Kent M., "Assessing genetic diversity in the web blight pathogen Thanatephorus cucumeris (anamorph = Rhizoctonia solani) subgroups AG-1-IE and AG-1-IF with molecular markers" (2012). Papers in Plant Pathology. 273.

http://digitalcommons.unl.edu/plantpathpapers/273 


\title{
Assessing genetic diversity in the web blight pathogen Thanatephorus cucumeris (anamorph = Rhizoctonia solani) subgroups AG-1-IE and AG-1-IF with molecular markers
}

\author{
N. González, ${ }^{1}$ G. Godoy-Lutz, ${ }^{2}$ J. R. Steadman, ${ }^{1}$ R. Higgins, ${ }^{1}$ and K. M. Eskridge ${ }^{3}$ \\ 1. Plant Pathology Department, University of Nebraska, Lincoln, NE 68583-0722, USA \\ 2. Instituto Dominicano de Investigaciones Agropecuarias y Forestales (IDIAF), Santo Domingo, Dominican Republic \\ 3. Department of Statistics, University of Nebraska, Lincoln, NE 68583-0963, USA
}

Corresponding author - J. R. Steadman, email jsteadman1@unl.edu

\begin{abstract}
Web blight, an important foliar disease of dry beans in the Americas, is a challenge to manage. We studied genetic variation of 92 isolates of Rhizoctonia solani subgroups AG-1-IE and AG-1-IF using DNA fingerprinting methods and mycelial compatibility grouping. The isolates were collected over 13 years from bean fields in the Dominican Republic, Honduras and Puerto Rico. Cluster and AMOVA analysis of combined data from two universal rice primers and two internal sequence repeats revealed significant genetic variation among and within populations of both subgroups. Variation was influenced by geographic origin and sampling year for AG-1-IE isolates and geographic origin for AG-1-IF isolates. Mycelial compatibility of paired isolates was mostly scored as incompatible in both subgroups and supported many unique phenotypes. Only two isolates of AG-1-IE displayed mycelial compatibility and DNA fingerprints, suggesting clonal origin. Genetic variation in these AG-1-IE and AG-1-IF isolate populations may explain the lack of durable resistance to web blight reported in dry beans.
\end{abstract}

Keywords: Phaseolus vulgaris, DNA markers, DNA polymorphism, anastomosis groups, population genetics

\section{Introduction}

Web blight (WB), caused by aerial isolates of Rhizoctonia solani Kühn (teleomorph: Thanatephorus cucumeris
Frank Donk), is an economically important disease of dry edible beans (Phaseolus vulgaris L.) grown in the humid tropical highlands and lowlands of Latin America and the Caribbean (LAC) (Gálvez et al. 1989). The disease causes millions of dollars in yield losses due to destruction of leaves or seed blemishes that reduce value (Godoy-Lutz et al. 1996). Over the past decades, the disease has spread within the LAC region and recently to countries in Africa and South America, especially Ecuador (Masangano and Miles 2004; Wortman 2006; JS Beaver, Univ. Puerto Rico, personal communication). The disease is spread by mycelial bridges between plants, rain-splashed sclerotia, infested soil debris (Gálvez et al. 1989) and airborne basidiospores (Cardenas-Alonso 1989; Echandi 1965). Deployment of resistant cultivars is the most economical management option; however, there are no available commercial varieties with WB resistance. Other management options include cultural practices such as minimum tillage and the use of costly fungicides, neither of which are highly effective, and chemical use can have negative environmental concerns (Beaver and Osorio 2009; Godoy-Lutz et al. 2008).

As a species, R. solani is composed of a large complex assemblage of anastomosis groups (AGs) that are genetically distinct nonmating populations showing a wide diversity in morphology, pathogenicity and physiology 
(Kuninaga et al. 1997; Ogoshi 1987; Sneh et al. 1991). Isolates of R. solani can exist simultaneously as bi- or multinucleate homokaryons or heterokaryons possessing either homothallic (asexual), bipolar or heterothallic mating systems resulting in a variety of mechanisms for generating genetic diversity within AGs (Adams 1996; Cubeta and Vilgalys 1997). Web blight is mostly caused by five genetically different subgroups: AG-1-IA, AG1-IB, AG-1-IE, AG-1-IF and AG-2-2WB (Godoy-Lutz et al. 2008). To a lesser extent, other isolates of AG-4 and AG-2-2 IV have been associated with WB symptoms (Carling et al. 2002; Gálvez et al. 1989). Isolates of AG1-IE and AG-1-IF are the most widespread and collectively more virulent than other subgroups causing WB in the LAC region and have overcome cultivars with partial resistance (Beaver et al. 2008; Godoy-Lutz et al. 1996, 2000). Isolates of AG-1-IE and -IF produce abundant mycelia and sclerotia under field conditions that could contribute to the spread of clonal isolates through soil, water and contaminated symptomless seed to distant locations (Cardenas-Alonso 1989; Gálvez et al. 1989; Godoy-Lutz et al. 1996, 2003).

Identifying the genetic structure of pathogen populations will provide a basis to determine characteristics and the evolutionary processes that shaped those populations in agroecosystems (McDonald and Linde 2002).

Molecular biology has provided techniques that exploit the naturally occurring variation in DNA for identifying strains and clonal lineages within a species and for discriminating and classifying populations at different taxonomic levels (Xu 2006). Molecular approaches have been used to establish that AGs and other subgroups are genetically isolated and represent highly divergent evolutionary units (Cubeta and Vilgalys 1997; Rosewich et al. 1999).

Despite the economic importance of the WB pathogen, there is no published information regarding beaninfecting populations of AG-1-IE and AG-1-IF, including the distribution of genetic diversity within and among their populations and how their reproduction mode may have influenced their population fitness. Isolates within each of these subgroups are morphologically and culturally indistinguishable regardless of the country of origin. When the ITS 5.8S rDNA region was used to characterize $68 \mathrm{WB}$ isolates, little or no polymorphism was detected among isolates from geographically distant locations; thus, field populations of these subgroups appear to be genetically homogenous (Godoy-Lutz et al. 2008). However, no attempts have been made to determine the extent of intra-population variability in $R$. solani AG-1-IE and AG-1-IF. DNA fingerprints generated by dominant neutral molecular markers have been employed for initial assessment of genetic diversity and population structure for AG-2, AG-3, AG-4, AG-8, AG-9 and AG-1-IB (Ceresini et al. 2002; Duncan et al. 1993; Grosch et al. 2011; Justesen et al. 2003; Meinhardt et al. 2002; Yang et al. 1995). A comprehensive review of molecular methods used for characterization and classification of Rhizoctonia spp. has been published by Sharon et al. (2006). Other dominant molecular markers that have been used in recent fingerprinting studies for $R$. solani are universal rice primers (URP) (Kang et al. 2002) and inter simple sequence repeats (ISSR) (Gupta et al. 1994). Despite some limitations inherent with their dominant nature, the aforementioned markers have been extensively used for eukaryotic organisms because they are cost effective, highly reproducible, have multiple polymorphic loci, are appropriate for closely related individuals and no prior knowledge of the genome is needed for their use (Gupta et al. 1994; Nybom 2004; Sharma et al. 2005; $\mathrm{Xu}$ 2006). DNA fingerprinting complemented with another independent criteria such as mycelial compatibility pattern has been suggested for providing preliminary information on mating system and genetic structure of $R$. solani (Cubeta and Vilgalys 1997; Vilgalys and Cubeta 1994). The clonal composition, defined as where two or more isolates are somatically compatible and share the same DNA marker phenotype, has been examined in field populations of AG-3 and AG1-IA (Campos and Ceresini 2006; Ceresini et al. 2002).

The objective of this study was to determine genetic structure of populations of $R$. solani isolates within subgroups AG-1-IE and AG-1-IF, collected from Honduras, Puerto Rico and the Dominican Republic over 13 years based on DNA fingerprinting and mycelial compatibility.

\section{Materials and methods}

\section{Isolate collection and DNA extraction}

The 92 multinucleate isolates examined in this study originated from web blight symptomatic leaves of individual $P$. vulgaris plants collected over 13 years and stored at the University of Nebraska-Lincoln. Isolates were collected in Honduras (37 isolates), Dominican Republic (15 isolates) and Puerto Rico (40 isolates) (Table 1) from locations where breeders screen lines for WB resistance and the disease is endemic. Isolates were stored in sugar beet seeds at $4^{\circ} \mathrm{C}$ and were activated by plating on water agar (WA) and transferring to Difco potato dextrose agar (PDA) after $48 \mathrm{~h}$. Three to four days later (before isolates began producing sclerotia), five agar plugs from the edge of the growing mycelia were introduced into $50 \mathrm{ml}$ of sterile V-8 liquid medium $\left(1.5 \mathrm{~g} \mathrm{CaCO}_{3}+100 \mathrm{ml} \mathrm{V-8}\right.$ juice $+400 \mathrm{ml}$ of de-mineralized sterile water) in a deep Petri dish and were grown at $25^{\circ} \mathrm{C}$ without shaking under constant light until a mat of mycelia reached the edges of the plate and before sclerotia developed. Mycelial mats were harvested by 
Table 1. Isolates of Rhizoctonia solani from Phaseolus vulgaris examined in this study

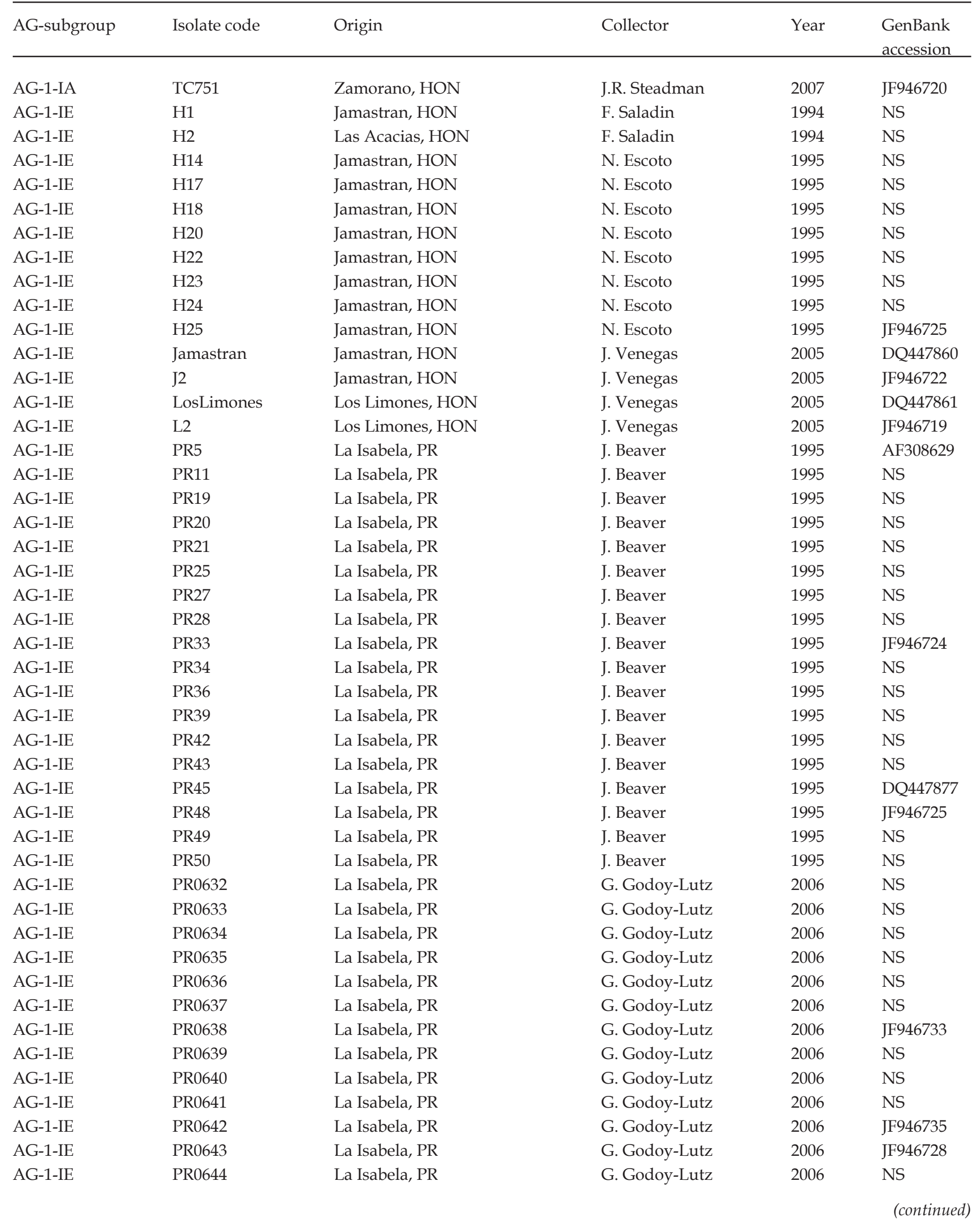


Table 1. Isolates of Rhizoctonia solani from Phaseolus vulgaris examined in this study (continued)

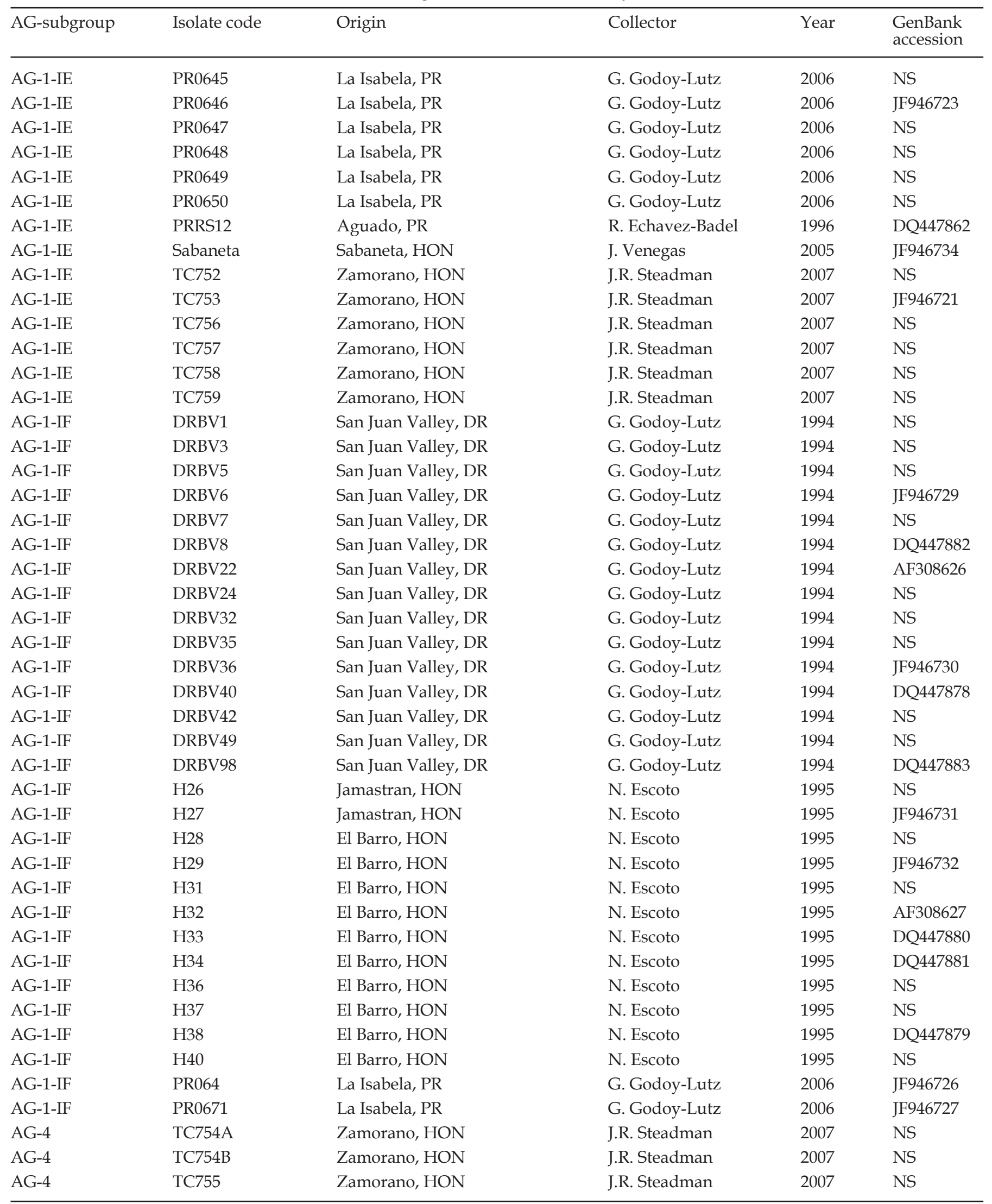


filtration and stored at $-20^{\circ} \mathrm{C}$, and $50 \mathrm{mg}$ portions were used for genomic DNA extractions. A commercial DNA extraction kit, UltraClean Plant DNA Isolation Kit (Mo Bio Laboratories, Carlsbad, CA, USA) was used to extract DNA and eliminate culture pigments absorbed by mycelia during growth.

\section{Determination of subgrouping by specific primers}

Assuming that most isolates belonged to AG-1 based on previous classification by Godoy-Lutz et al. (2008), initial PCR amplification was performed with primers WB-A (for determination of AG-1-1E) and WB-B (for AG-1-1F). A few isolates that did not amplify were tested with other primers suggested by Carling et al. (2002) and Godoy-Lutz et al. (2008). PCR amplifications were performed by adding $1.0 \mu \mathrm{l}$ DNA (80-100 ng), $5 \mu \mathrm{l}$ of 10× Taq DNA polymerase buffer $(50 \mathrm{mM} \mathrm{KCl}, 10 \mathrm{mM}$ Tris- $\mathrm{HCl}\left(\mathrm{pH} 9.0\right.$ at $\left.25^{\circ} \mathrm{C}\right), 1.5 \mathrm{mM} \mathrm{MgCl}_{2}$ and $0.1 \%$ (v/v) Triton X-100 when diluted 1:10), $4 \mu \mathrm{l}$ of $1.25 \mathrm{mM}$ of each dNTP, $0.8 \mu \mathrm{l}$ of each $20 \mu \mathrm{M}$ primers (forward and reverse) (Invitrogen, Carlsbad, CA, USA) and $0.4 \mu 1$ of Taq DNA polymerase ( $5 \mathrm{U} / \mu \mathrm{l}$ ) (Promega, Madison, WI, USA) to a $50 \mu 1$ reaction mixture prepared with sterile nuclease free water. Amplifications were performed in a PTC-100 Thermal cycler (Bio-Rad Laboratories, Hercules, CA, USA) under the following conditions: 1 cycle of $94^{\circ} \mathrm{C}$ for $2 \mathrm{~min}$; followed by 30 cycles of $94^{\circ} \mathrm{C}$ for $40 \mathrm{~s}$, $53-62^{\circ} \mathrm{C}$ (depending upon the primer) for $1 \mathrm{~min}$ and $72^{\circ} \mathrm{C}$ for $1 \mathrm{~min}$; completed by a final extension at $72^{\circ} \mathrm{C}$ for $5 \mathrm{~min}$.

\section{DNA polymorphism analysis}

Isolates were tested with 10 markers that have been reported to be polymorphic and reliable in characterizing genetic diversity in R. solani (Sharma et al. 2005; Zala et al. 2008). Only four molecular markers, URP: URP2R (5'-CCCAGCAACTGATCGCACAC-3') and URP6R (5'-GCAAGCTGGTGGGAGGTAC-3') (Sharma et al. 2005), and ISSR: ISSR10 (5'-CACCACCACCACCAC-3') (Sharma et al. 2005) and (GACA) 4 (Ureña-Padilla et al. 2002), were informative for assessing diversity. Other markers that were tested but either did not amplify or were not polymorphic for most isolates in-

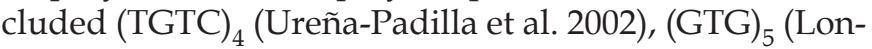
gato and Bonfante 1997; Meinhardt et al. 2002), URP13R (5'-TACATCGCAAGTGACACAGG-3'), URP17R (5'-AATGTGGGCAAGCTGGTGGT-3'), ISSR2 (5'-ACTGACTGACTGACTG-3') (Sharma et al. 2005) and TC06 $(C A G)_{11}$ (5'-CAGAGATACGTCCAGCAACG-3') (Zala et al. 2008). Attempts to modify amplification conditions such as adjusting DNA quantity and concentrations of Taq DNA polymerase, $\mathrm{MgCl}_{2}$ or dNTPs were unsuccessful, and these markers were not used in characterizing isolates. PCR amplifications for URP2R,
URP6R, ISSR10, and (GACA) 4 were performed by adding $3.0 \mu \mathrm{l}$ of DNA $(<250 \mathrm{ng})$ to $25 \mu \mathrm{l}$ of PCR Master Mix 2X $(50 \mu \mathrm{l} / \mathrm{ml}$ Taq DNA polymerase in reaction buffer $\mathrm{pH}$ 8.5, $400 \mu \mathrm{M}$ each dATP, dGTP, dCTP and dTTP, $3 \mathrm{mM}$ $\mathrm{MgCl}_{2}$ ) (Promega), $1.5 \mu \mathrm{l}$ of $20 \mu \mathrm{M}$ primers (forward and reverse) (Invitrogen) and sterile nuclease free water up to $50 \mu \mathrm{l}$. Amplification conditions for each marker, performed in a PTC-100 Thermal cycler (Bio-Rad), were as follows: (GACA) $)_{4}-1$ cycle of $95^{\circ} \mathrm{C}$ for $5 \mathrm{~min}$; followed by 34 cycles of $94^{\circ} \mathrm{C}$ for $1 \mathrm{~min}, 40^{\circ} \mathrm{C}$ for $1 \mathrm{~min}$ and $72^{\circ} \mathrm{C}$ for $1.5 \mathrm{~min}$; completed by a final extension at $72^{\circ} \mathrm{C}$ for $10 \mathrm{~min}$; URP2R and URP6R -1 cycle of $94^{\circ} \mathrm{C}$ for $4 \mathrm{~min}$; followed by 35 cycles of $94^{\circ} \mathrm{C}$ for $1 \mathrm{~min}, 45^{\circ} \mathrm{C}$ for $1 \mathrm{~min}$ and $72^{\circ} \mathrm{C}$ for $2 \mathrm{~min}$; completed by a final extension at $72^{\circ} \mathrm{C}$ for $10 \mathrm{~min}$; ISSR $10-1$ cycle of $94^{\circ} \mathrm{C}$ for $4 \mathrm{~min}$, followed by 35 cycles of $94^{\circ} \mathrm{C}$ for $1 \mathrm{~min}, 51^{\circ} \mathrm{C}$ for $1 \mathrm{~min}$ and $72^{\circ} \mathrm{C}$ for $2 \mathrm{~min}$; completed by a final extension at $72^{\circ} \mathrm{C}$ for $10 \mathrm{~min}$.

All PCR amplification products were size-fractionated by gel electrophoresis in $1.5 \%(\mathrm{w} / \mathrm{v})$ Ultra Pure Agarose (Invitrogen) in $0.5 \times \mathrm{TBE}$ buffer $(0.045 \mathrm{~mol} / 1$ Tris, $0.045 \mathrm{~mol} / 1$ Boric acid, and $0.001 \mathrm{~mol} / 1$ EDTA) at 100 V. A 100-bp DNA Ladder (Invitrogen) was included in each gel for standardization. Ethidium-bromidestained amplified fragments were recorded digitally using the ChemiDoc EQ System with the Quantity One 1-D Analysis software version 4.6.2 (Bio-Rad). All amplifications were repeated twice and included a positive control (known subgroup isolate) and a negative control (no DNA).

\section{ITS 5.8S rDNA sequence analysis}

The 5.8 rDNA-ITS region of 18 isolates, in addition to 13 previously described isolates (Godoy-Lutz et al. 2008), representing AG-1 subgroups was amplified with primers ITS4 and ITS5 (White et al. 1990). The PCR amplification protocol described earlier for specific primers, except for $20 \mu \mathrm{mol} / 1$ ITS4 and ITS5 primers (Invitrogen) were used. The amplifications were performed in a PTC-100 Thermal cycler under conditions similar to those used for subgroup specific primers, except that the annealing temperature was set at $55^{\circ} \mathrm{C}$. PCR products were purified with the QIAquick PCR Purification Kit (Qiagen, Valencia, CA, USA) and sequenced using both primer strands by an Applied Biosystems (Foster City, CA, USA) Model 3100 Genetic Analyzer at the Genomics Core Research Facility at the University of Nebraska-Lincoln. Sequence data for the complete ITS 5.8S rDNA region of the isolates was manually checked and edited to remove portions of the 18S and 28S rDNA using the Multiple Sequence Alignment of Clustal W software (Thompson et al. 1994). Sequence data was analyzed by a parsimony method with the program PAUP version 4.02 beta (Swofford 2003). Nucleotide substitutions were 
equally weighted and unordered and alignment gaps were considered as missing data. Distance matrix analysis was conducted with the maximum parsimony algorithm, omitting all sites with gaps. The phylogenetic tree was rooted with isolate R9 (AG-2-2 IV, GenBank AB054863). Confidence intervals in tree topologies were estimated by bootstrap analysis with 1000 replicates. Only nodes with bootstrap values of more than $50 \%$ were considered to be significant. The final tree was visualized with the program TreeDyn (Chevenet et al. 2006). Gene sequences of other $R$. solani WB isolates were added to the group being examined. The sequences correspond to AG-1-1A [GenBank accession AF308631 (isolate Cuba 2) and DQ447859 (isolate Cuba1)], AG-1-1E [GenBank accession DQ447877 (isolate PR45), DQ447873 (isolate N1), AF308629 (isolate PR5), DQ447862 (isolate PRRs12), DQ447861 (isolate Los Limones), DQ447860 (isolate Jamastran)] and AG1-1F [GenBank accession DQ447878 (isolate DRBV40), AF308626 (isolate DRBV22), AF308627 (isolate H32), DQ447879 (isolate H38), DQ447882 (isolate DRBV8)].

\section{Mycelial compatibility test}

The mycelial compatibility of 21 isolates of AG-1-1E and 13 isolates of AG-1-1F, chosen randomly from UPGMA tree clusters, was conducted on culture media. Each isolate was grown on PDA for 2-3 days and paired with one another in all possible combinations by placing $5 \mathrm{~mm}$ agar plugs taken from the edge of the growing mycelia onto PDA in a $90 \mathrm{~mm}$ Petri dish, spaced $5 \mathrm{~cm}$ apart. Plates were incubated at $21 \pm 1^{\circ} \mathrm{C}$ until the mycelia from each isolate met or formed sclerotia (ca. 2 weeks). Two plates of each isolate combination were prepared. A modified rating based on Ceresini et al. (2002) was used. Mycelial interaction was scored as compatible when mycelia merged, or incompatible when a visible clear zone or a sclerotial barrier was formed in the contact zone between paired colonies.

\section{Data analysis}

Banding patterns for each marker were observed and band sizes noted. Each amplicon representing one allele was scored as either " 0 " for absence or " 1 " for presence on each gel. DNA fingerprints were converted to binary data matrices, which were used directly for comparison by two band-based similarity coefficients: Jaccard's coefficient (1901) and Dice's coefficient (1945), which is equivalent to the Nei-Li coefficient (1979). Cluster analysis using genetic distance was performed by the SAS/STAT Program (Anonymous 2004, Cary, NC, USA) using the UPGMA (unweighted pair grouping by mathematical averages) clustering algorithm to generate dendrograms to connect isolates. The Mantel test for matrix correspondence was used to correlate genetic distances calculated from the URP and ISSR marker data to determine whether they could be combined further using 5000 permutations. The binomial matrix was also analyzed with the software PAST (PAleontological STatistics Version 2.01) (Hammer et al. 2001) for comparison with other similarity indexes for UPGMA and neighbor-joining cluster algorithms and visualization of dendrograms.

A nonparametric analysis of molecular variance (AMOVA) was used to determine genetic variability among populations as described by Excoffier et al. (1992). A Euclidean distance matrix generated from the binary matrix was calculated for AMOVA, and both were performed with the GenAlEx 6.3 (Peakall and Smouse 2006) software. AMOVA allows the hierarchical partitioning of genetic variation among and within populations and the estimation of variance components and Wright's $\mathrm{F}_{\mathrm{ST}}$ statistic analogs [designated as Phi $(\Phi)$ statistic] (Excoffier et al. 1992). $\Phi$ can range from 0, indicating no differentiation within the overall population and its subpopulation, to a theoretical maximum of 1 , indicating complete differentiation (Peakall and Smouse 2009). Data sets for AG-1-IE and AG-1-IF were analyzed separately. For AG-1-IE, hierarchical AMV was partitioned among geographical locations, among sampling year and within isolate populations. For AG-1-IF, the variance was partitioned among geographical locations and within isolate populations. All data sets were tested using 9999 permutations.

Other statistics for measuring genetic variation with dominant markers, such as number of total and specific or unique alleles, percentage of polymorphic loci and Shannon's index of diversity were also calculated with GenAlEx. We estimated Shannon's index of diversity to quantify phenotypic diversity within populations as revealed by each primer. This index does not require the assumption of Hardy-Weinberg equilibrium.

\section{Results}

\section{Determination of subgrouping based on specific primers and ITS $5.8 S$ rDNA region}

Isolates from Puerto Rico, Honduras and the Dominican Republic that were not previously assigned to an anastomosis subgroup were classified as AG-1-1E based on the size of the band at $540 \mathrm{bp}$, and AG-1-IF based on the size of band at $510 \mathrm{bp}$ after being amplified with WB-A and WB-B. The anastomosis subgroup results and isolate collection data are presented in Table 1. Isolate 
TC751 was assigned to subgroup AG-1-IA, and isolates TC754A, TC754B and TC755 were assigned to subgroup AG-4 on the basis of specific primer amplifications (Godoy-Lutz et al. 2008; Kuninaga et al. 1997).

Alignment of the sequences and phylogenetic tree analysis of the full ITS 5.8S rDNA region of 18 selected R. solani WB isolates in this study from Puerto Rico, Honduras and Dominican Republic and sequences of 12 known $R$. solani WB isolates in the GenBank (Godoy-Lutz et al. 2008) agree with the AG subgroup assignment based on subgroup-specific primer amplifications.

The sequence alignment showed 577 sites conserved and 61 parsimonious informative sites. The strict consensus tree out of 1000 equally parsimonious trees was 186 steps long, CI 90.892 and RI 0.108 (Figure 1). Sequences of the $18 \mathrm{WB}$ isolates have been deposited in the NCBI GenBank database, and the accession numbers are listed in Table 1.

\section{Genetic variation and population structures using URP and ISSR primers}

Of the 10 primers tested, only four produced unambiguous, high-intensity amplicons yielding polymorphic patterns that showed $100 \%$ repeatability. The rest of the primers either failed to generate amplicons or generated weak nonrepeatable patterns for most isolates

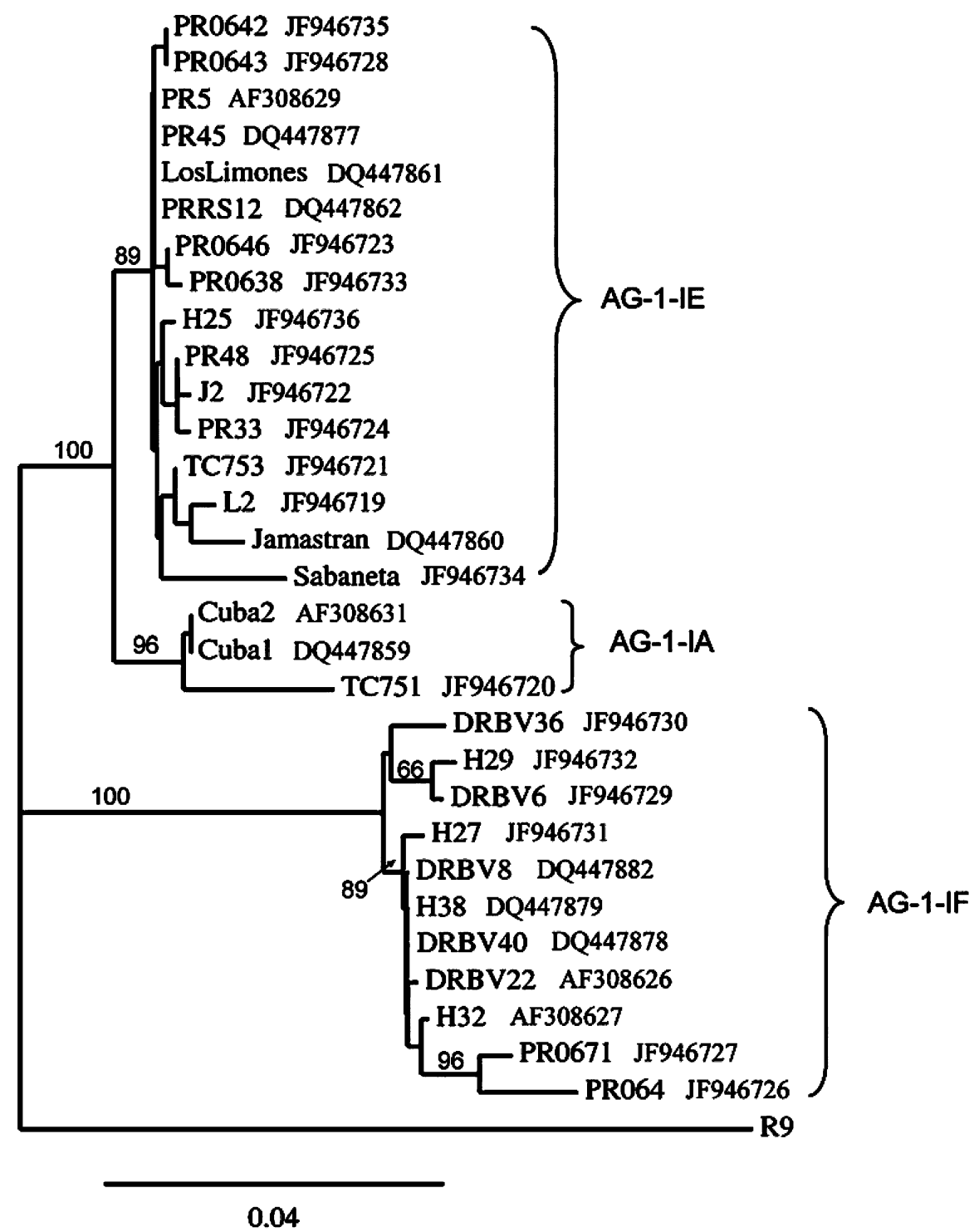

Figure 1. Strict consensus of 1000 equally parsimonious trees based on ITS rDNA sequence data from 30 web blight isolates of AG-1. The tree length is 186 steps, CI 0.892 and RI 0.108. The tree is rooted to isolate R9 (AG-2-2 IV). Numbers above branches indicate bootstrap percentiles from 1000 repeats using PAUP version 4 (Swofford 2003). 
within both subgroups. The data obtained for each of the primers is summarized in Table 2. Unique or specific amplicons for each population within subgroups were detected. Internal simple sequence repeat primers (ISSR10 and [GACA] $]_{4}$ ) resulted in the smallest number of bands and yielded $4-46 \%$ polymorphism, whereas universal rice primers (URP2R and URP6R) yielded 36$80 \%$ polymorphism in isolates of both subgroups. Shannon's index of diversity varied according to the primer with URP2R showing the highest index with an average of 0.30 for AG-1-IE and 0.25 for AG-1-IF. These results were reflected in the primer data dendrograms when they were generated for each primer (Supplementary Figure S1-S10).

When Mantel correlation analysis was used between matrices for both primer systems, high positive correlations $(\mathrm{r}=0.7509$ and $0.7534 \mathrm{P}<0.001$, respectively) were obtained. This allowed data from 101 loci, from all four primers, to be combined for cluster analysis and other population estimates. UPGMA based on Jaccard's distances generated the highest cophenetic correlation value of 0.9725 with a 1000 replicate bootstrap to provide the best representation of similarity (Figure 2). With a few exceptions, most isolates clustered together as either AG-1-IE or AG-1-IF supporting a population structure defined by geographic location and year of sampling or by geographic location, respectively.

AMOVA revealed significant genetic variation among and within grouping factors for each subgroup. The AG-1-IE subgroup showed significant variation due to geographic location (28\%), sampling year $(35 \%)$ and within isolate population (37\%) (Table 3). AG-1-IF subgroups showed that $27 \%$ of the total variation was due to geographic location and $73 \%$ to within isolate population. Values of $\Phi$ above 0.25 were significant for all grouping factors in both subgroups (Table 3 ).

\section{Mycelial compatibility test}

When paired in culture, isolates of AG-1-IE and AG1-IF formed either a sclerotial barrier or a clear demarcation or line in the contact zone between the paired isolate colonies. Few paired isolates scored as compatible (Figure 3). For AG-1-IE, only 5 of 210 pair combinations (excluding self pairings) from the same sampled location or sampling year displayed a compatible reaction (Supplementary Figure S11). These five isolate pairs were PR20/PR28, PR0635/PR0637, PR0635/ PR0638 from Puerto Rico; Jamastran/J2 and TC756/ TC757 from Honduras. Of the remaining pair combinations, 26 were incompatible and formed a clear zone or demarcation in the contact zone of the paired isolates, and 179 were incompatible and formed a sclerotial barrier in the contact zone.

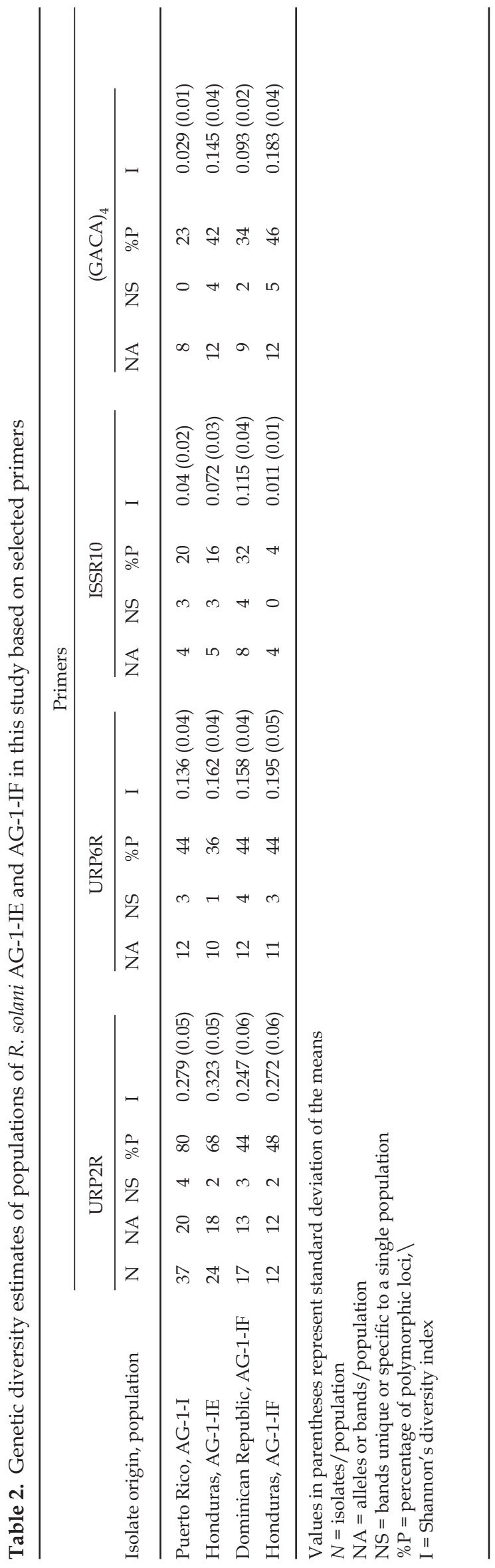




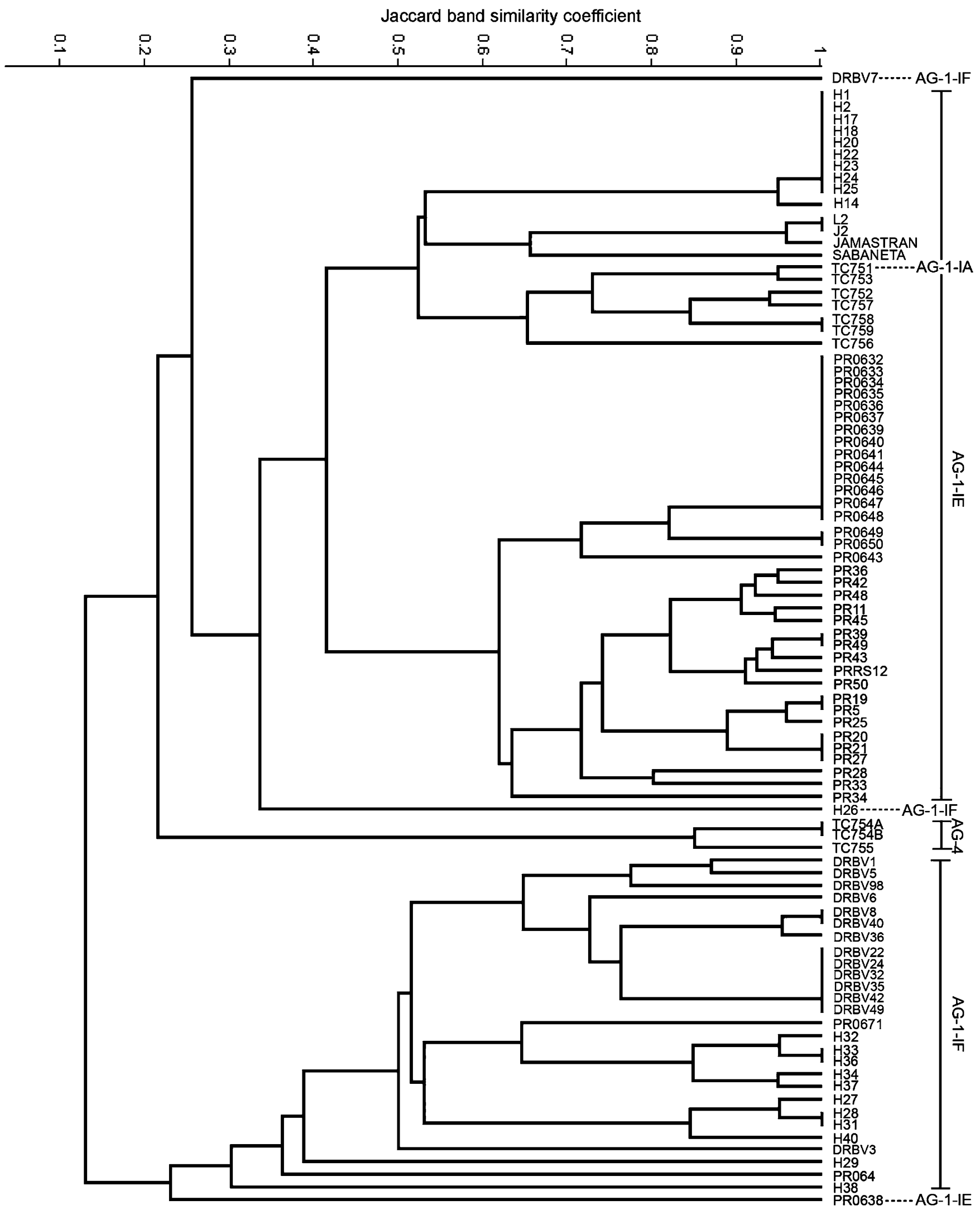

Figure 2. Dendrogram depicting relationships among Rhizoctonia solani WB isolates, generated from Jaccard's genetic distance matrix by using UPGMA cluster algorithm of PAST program (Hammer et al. 2001). Cophenetic $r=0.9755$, bootstrap 1000 replicates. 

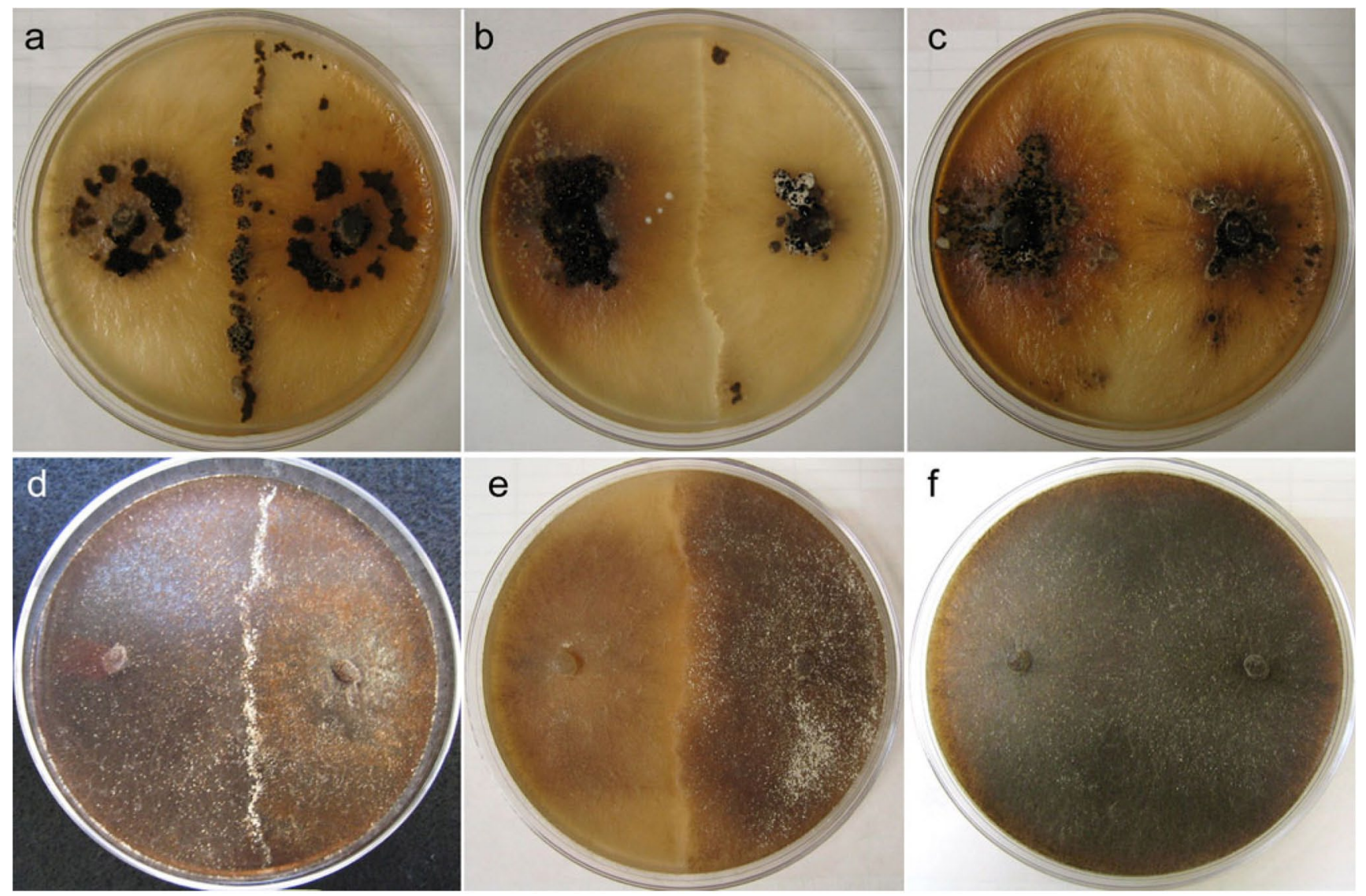

Figure 3. Macroscopic mycelial compatibility tests between isolates of Rhizoctonia solani AG-1-IE (top row) and AG-1-IF (bottom row). Interactions were scored as incompatible $(\mathrm{a}, \mathrm{d})$, showing a distinct barrier of sclerotia between paired isolates; incompatible (b, e), showing clear demarcation between paired isolates; or compatible (c, f), mycelia merged with no distinct demarcation or sclerotial barrier between paired isolates.

Table 3 Analysis of molecular variance (AMOVA) of R. solani WB isolates of AG-1-IE and AG-1-F based on combined universal rice primers and inter simple sequence repeat primer data

\begin{tabular}{lllllll}
\hline Subgroups & Source of variation & $\mathrm{df}$ & SS & \% Variation & $\Phi$ & P value \\
\hline AG-1-IE & Among locations & 1 & 114.43 & 28 & 0.281 & 0.490 \\
& Among sampling years & 2 & 94.45 & 35 & 0.633 & 0.000 \\
& Within isolate populations & 57 & 173.86 & 37 & 0.000 \\
\multirow{5}{*}{ AG-1-IF } & Total & Among locations & 1 & 382.75 & & 0.265 \\
& Within isolate populations & 27 & 146.13 & 73 & 0.000 \\
& Total & 28 & 179.04 & & \\
\hline
\end{tabular}

P value for randomization test for $\Phi$ is based on 9999 permutations across the full data set

Similarly for AG-1-IF, 4 of 78 pair combinations from the same sampled location displayed a compatible reaction: $\mathrm{H} 29 / \mathrm{H} 32, \mathrm{H} 29 / \mathrm{H} 33, \mathrm{H} 31 / \mathrm{H} 38$ and H32/H33 from Honduras (Supplementary Figure S12). Of the remaining pair combinations, 30 were incompatible and formed a clear zone or demarcation in the contact zone of the paired isolates, and 44 were incompatible and formed a sclerotial barrier in the contact zone.

\section{Discussion}

Isolates of AG-1-IE and AG-1-IF that are morphologically and culturally indistinguishable and cause web blight of dry beans, produced unique phenotypic fingerprint patterns with URP and ISSR primers. In addition, these isolates produced predominantly incompatible mycelial interactions in culture and, when 
considered with the DNA fingerprint data, exhibit significant genetic variation among and within isolate populations.

The ITS 5.8S rDNA sequence of the 18 new isolates in this study (GenBank accessions JF946719 to JF946736) revealed polymorphisms that separated the AG-1 isolates into three clades representing subgroups of AG1-IA, AG-1-IE and AG-1-IF in agreement with a previous report (Godoy-Lutz et al. 2008). Only a few isolates had a $100 \%$ match of their sequences. Most of the variability displayed within clades was associated with isolates collected from 2005 to 2007. The subgroup separation was congruent with the dendrograms generated by cluster analysis of combined marker data. The ITS rDNA region is considered appropriate for establishing phylogenetic relationships of Rhizoctonia AGs and subgroups within AGs (Cubeta and Vilgalys 1997; Kuninaga et al. 1997), and PCR primers based on highly conserved regions of the rDNA unit have been designed for diagnostic purposes for many fungi (Klich and Mullaney 2004). However, assessing population diversity of closely related species through polymorphism at the ITS 5.8S rDNA level has its limitations. It provides a relatively small amount of sequence data (ITS spacers $<300 \mathrm{bp}$ ) with low discriminatory power, and the co-occurrence of multiple sequences present in a single individual makes its use unreliable and hinders comparative sequence analysis to answer questions at this hierarchical level (Muir and Schlötterer 1999). The occurrence of multiple sequences at the ITS1 level has been documented for AG-1 (Grosch et al. 2007), AG-3 (Justesen et al. 2003), and AG-4 (Boysen et al. 1996). For AG-1-IE and AG-1-IF, however, this phenomenon has not been observed; on the contrary, 80 and $66 \%$, respectively, of isolate sequences have had a 100\% match (Godoy-Lutz et al. 2008).

Not all of the primers used successfully with other $R$. solani subgroups amplified products or were informative for distinguishing polymorphism among the isolates used in this study. Based on the degree of polymorphism indicated by the percent of polymorphic loci generated and Shannon's index, URP2R was more suitable for studying genetic diversity in populations of both subgroups. In general, both URP and ISSR marker systems have been useful for evaluating variation in fungal populations (Aggarwal et al. 2010; Jana et al. 2005; Kiyosi et al. 2005; Sharma et al. 2005; Stodart et al. 2007). The UPGMA dendrogram showed two main clusters separating subgroups. The subclustering, with a few exceptions, was based on geographic location and year of sampling for isolates of AG-1-IE and on geographic location for isolates of AG-1-IF. Other fragmentation within subclusters, such as one isolate of each of AG-1-IA, AG-1-IE and of AG1-IF, as well as three of AG-4 clustering within the
AG-1-IE group, cannot be explained although isolates of AG-1-IA are more closely related to AG-1-IE than to other subgroups of AG-1 (Godoy-Lutz et al. 2008; Grosch et al. 2007).

The AMOVA test rejected the null hypothesis of no genetic differentiation among the populations where $\Phi=0$ ( $\mathrm{F}_{\mathrm{ST}}=0$, Wright's fixation index). The results for populations of both subgroups can be used to infer the existence of high genetic differentiation $(\Phi>0.25)$ that can result from multiple factors including reproduction strategies, mating system, gene flow, and geographic isolation (Cubeta and Vilgalys 1997). Within-isolate population variation for both subgroups was also statistically significant, which supports heterogeneous populations. A high percentage of within-isolate population variance was obtained for isolates of AG-1-IF congruent with the subclustering in the dendrogram. Isolates of this group were recently classified as a distinct population within Central and South America and the Caribbean, based on phylogenetic analysis (Grosch et al. 2007). Even though we were unable to induce sporulation under laboratory conditions, other authors have documented the development of the teleomorphic stage (basidia and basidiospores) in bean fields where AG-1 isolates are prevalent (Cardenas-Alonso 1989; Echandi 1965; Godoy-Lutz et al. 2000). Basidiospores, airborne microsclerotia and vegetative mycelia (rain-splashed locally and on seed for long distances) would contribute significantly to the temporal and spatial distribution of the pathogen (Gálvez et al. 1989). Also, the development of basidiospores by meiotic reproduction provides a mechanism for generating genetic diversity in a population (Cubeta and Vilgalys 1997). However, basidiospores are fragile and do not travel long distances (Echandi 1965).

Variation due to geographic location was significant. In a previous study, we reported that the majority of isolates within subgroups of AG-1-IE, AG-1-IF and AG-2-2 WB had identical sequences in the ITS 5.8S rDNA region even though they were collected from wild common beans and commercial dry beans representing different Phaseolus host gene pools in geographically separate locations (Godoy-Lutz et al. 2008). This result is very unusual considering the diploid and multinucleate nature of R. solani. One theory proposed is that gene flow due to seed movement of $R$. solani was involved in distributing similar genotypes among countries in the region regardless of the geographic distance. In the present study, however, the finding of significant genetic variation can be indicative of reduced gene flow that could result from geographical barriers between populations. This would be consistent with the fact that each of the three countries of isolate origin are geographically separated by water and would be unlikely to exchange bean seed due to different seed class preferences. 
The host cultivar did not appear to influence the genetic variation among isolates of either subgroup (data not shown). Most of the studies on population genetics of R. solani or other plant pathogens using dominant markers such as RAPD, URP, AFLP or ISSR have reported that geographic location or host specificity or both had an effect on population structure (Aggarwal et al. 2010; Duncan et al. 1993; Jana et al. 2005; Sharma et al. 2005; Stodart et al. 2007). Because of the limitations of dominant markers, these studies are difficult to compare with other studies where co-dominant markers (microsatellites) were used. In dominant marker systems, homozygosity and heterozygosity are indistinguishable, meaning banding patterns of diploid individuals, such as R. solani, that are generated are representative of individual phenotypes rather than genotypes (Kosman and Leonard 2005). In our study, the use of cluster analysis and AMOVA enabled us to draw conclusions about within-population structure as an exploratory analysis (Bonin et al. 2007). The availability of statistical analysis methods and associated software for dominant marker data can help to circumvent the limitations associated with these markers; however, this approach needs to be carefully evaluated (Bonin et al. 2007).

In this study, most mycelial interactions of selected paired isolates were scored as incompatible. Only five pair combinations of AG-1-IE and four pair combinations of AG-1-IF were compatible and occurred between isolates collected in the same location and sampling year. A mycelial compatibility test is also termed as macroscopic vegetative interaction (MacNish et al. 1997) or somatic compatibility grouping (Ceresini et al. 2002) and can reflect anastomosis behavior at the microscopic level in some AGs (MacNish et al. 1997). Paired isolates grown on culture media are scored as compatible (equivalent to a $\mathrm{C} 3$ reaction in a microscopic anastomosis), when no reaction is observed in the contact zone between similar colonies such as in self pairings, or incompatible (equivalent to a $\mathrm{C} 2$ reaction in a microscopic anastomosis) when a visible demarcation line or raised hyphae is observed in the contact zone between colonies reflecting antagonistic responses (MacNish et al. 1997; Yang et al. 1993). The latter implies genetic and cytoplasmic isolation (Worrall 1994).

None of the isolate pair combinations scored as compatible can technically be considered clones since they do not share the same marker phenotype, with the exception of isolates PR0635 and PR0637. Therefore, the mycelial compatibility test indicates that selected field isolates of AG-1-IE and AG-1-IF examined in this study are unique phenotypes, which could support the occurrence of outcrossing events during the pathogen's life cycle. Most likely these isolates are heterokaryons because they were collected from naturally infected plants where cobweb-like mycelia that covered plants may have originated from different sources.
Our results show some similarities to studies conducted on populations of $R$. solani AG-3 from potato and tobacco hosts (Ceresini et al. 2002) and populations of AG-1-IA from soybeans (Campos and Ceresini 2006) where few or no clones (sharing both somatic compatibility and molecular marker phenotype) were identified. Also the range of incompatibility varied in intensity from "weak" clear demarcation to raised hyphae in the contact zone between paired isolates. The biological significance of the term "weak" macroscopic incompatible reaction is not known (Ceresini et al. 2002). The authors attributed the range of somatic interactions between pairings of isolates as consistent with recombination. On the other hand, Ceresini et al. (2002) attributed the lack of somatic compatibility of field isolates of AG-3 to multiple loci and/or multiple alleles controlling somatic compatibility within the subgroup. Somatic compatibility in Rhizoctonia species is still not well understood.

Future work on genetic variation of the WB pathogen will require more structured sampling of isolates of various subgroups from different fields and countries within a geographic region where seed exchange commonly occurs. The development of co-dominant microsatellite markers would facilitate studies attempting to understand population structure and dynamics. Recently, the population structure of $R$. solani subgroup AG-1-IA, causal agent of sheath blight of rice and other blights of maize and soybean from South America, United States, China and India has been studied by employing subgroup specific DNA co-dominant microsatellite simple sequence repeat (SSR) markers (Bernardesde-Assis et al. 2009; Ciampi et al. 2008; González-Vera et al. 2010). Host specialization was shown to affect selection and the pattern of populations with different reproductive modes, leading the authors to propose a recombining reproductive mode for maize-infecting populations and a mixed reproductive mode (asexual and sexual) for the rice-infecting populations that includes recombination events followed by clonal expansion during the growing season (González-Vera et al. 2010). These results supported the hypothesis that characterizing populations of AG-1-IA can optimize the deployment of major resistance genes or single-pathway target fungicides as well as agricultural practices that lead to minimizing gene flow by reducing the spread of propagules via irrigation systems or contaminated machinery (González-Vera et al. 2010; McDonald and Linde 2002).

Similarly, knowledge of the population dynamics of AG-1-IE and AG-1-IF may explain the lack of durability of most bean germplasm accessions and recombinant inbred lines, which have exhibited some degree of field resistance in the past, but had to be reevaluated under contrasting field environments (Singh and Schwartz 2010). Little or no progress has been made in the identification of specific genes or QTL (quantitative trait loci) 
for resistance to $\mathrm{WB}$, inhibiting the deployment of varieties with high levels of resistance in the LAC region (Beaver and Osorio 2009). Bean breeders have attributed this hindrance to a lack of understanding of the pathogen variation and its significance for breeding for disease resistance (Singh and Schwartz 2010).

The economic importance and the widespread dissemination of the WB pathogen, which affects a crop that provides an important source of protein, fiber, antioxidants, and micronutrients to 500 million people in Latin America and Africa should merit more attention for sustainably managing this pathogen.

Acknowledgments - We thank Dr. Roy French, USDA-ARS Lincoln, NE, for help with analysis in PAUP; Margaret Denning, Joann Ortiz and Debra Pederson for word processing and graphics; and Margaret Denning and Serena McCoy for technical assistance and manuscript review.

\section{Supplementary material follows the References.}

\section{References}

Adams GC (1996) Genetics of Rhizoctonia species. In: Sneh B, Jabaji-Hare S, Neate S, Dijst G (eds) Rhizoctonia species: taxonomy, molecular biology, ecology, pathology and disease control. Kluwer, Dordrecht, pp 101-106

Aggarwal R, Singh VB, Shukla R, Gurjar MS, Gupta S, Sharma TR (2010) URP based DNA fingerprinting of Bipolaris sorokiniana isolates causing spot blotch of wheat. J Phytopathol 158:210-216

Anonymous (2004) SAS/STAT 9.1 user's guide. SAS Institute, Cary

Beaver JS, Osorio JM (2009) Achievements and limitations of contemporary common bean breeding using conventional and molecular approaches. Euphytica 168:145-175

Beaver JS, Alameda M, Rosas J (2008) Breeding beans for resistance to web blight. Ann Rep Bean Improv Coop 51:30-31

Bernardes-de-Assis J, Storari M, Zala M, Wang W, Jiang D, Li S, Jin M, McDonald BA, Ceresini PC (2009) Genetic structure of populations of the rice-infecting pathogen Rhizoctonia solani AG-1 IA from China. Phytopathology 99:1090-1099

Bonin A, Ehrich D, Manel S (2007) Statistical analysis of amplified fragment length polymorphism data: a toolbox for molecular ecologists and evolutionists. Mol Ecol 16:3737-3758

Boysen M, Borja M, del Moral C, Salazar O, Rubio V (1996) Identification at strain level of Rhizoctonia solani AG4 strains by direct sequence of asymmetric PCR products of the ITS regions. Curr Genet 29:174-18

Campos APS, Ceresini PC (2006) Incompatibilidade somática em Rhizoctonia solani AG-1 IA da soja. Summa Phytopathol 32:247-254

Cardenas-Alonso MR (1989) Web blight of beans (Phaseolus vulgaris L.) incited by Thanatephorus cucumeris (Frank) Donk in Colombia. Ph.D. dissertation, Cornell University, Ithaca

Carling DE, Kuninaga S, Brainard KA (2002) Hyphal anastomosis reactions, rDNA-internal transcribed spacer sequences, and virulence levels among subsets of Rhizoctonia solani anastomosis group-2 (AG-2) and AG-BI. Phytopathology 92:43-50

Ceresini PC, Shew HD, Vilgalys RJ, Cubeta MA (2002) Genetic diversity of Rhizoctonia solani AG-3 from potato and tobacco in North Carolina. Mycologia 94:437-449
Chevenet F, Brun C, Bañuls AL, Jacq B, Christen R (2006) TreeDyn: towards dynamic graphics and annotations for analyses of trees. BMC Bioinf 7:439

Ciampi MB, Meyer MC, Costa MJM, Zala M, McDonald BA, Ceresini PC (2008) Genetic structure of populations of Rhizoctonia solani anastomosis group 1 IA from soybean in Brazil. Phytopathology 98:932-941

Cubeta MA, Vilgalys R (1997) Population biology of the Rhizoctonia solani complex. Phytopathology 87:480-484

Dice LR (1945) Measures of the amount of ecologic association between species. Ecology 26:297-302

Duncan S, Barton JE, O'Brien P (1993) Analysis of variation in isolates of Rhizoctonia solani by random amplified polymorphic DNA assay. Mycol Res 97:1075-1082

Echandi E (1965) Basidiospore infection by Pellicularia filamentosa (=Corticium microsclerotia), the incitant of web blight of common bean. Phytopathology 55:698-699

Excoffier L, Smouse PE, Quattro JM (1992) Analysis of molecular variance inferred from metric distances among DNA haplotypes: application to human mitochondrial DNA restriction data. Genetics 131:479-491

Gálvez GE, Mora B, Pastor-Corrales MA (1989) Web blight. In: Schwartz HF, Pastor-Corrales MA (eds) Bean production problems in the tropics. CIAT, Cali, pp 195-259

Godoy-Lutz G, Arias J, Steadman JR, Eskridge KM (1996) Role of natural seed infection by the web blight pathogen in common bean seed damage, seedling emergence, and early disease development. Plant Dis 80:887-890

Godoy-Lutz G, Steadman JR, Powers K, Higgins B (2000) DNA variation and virulence among isolates causing web blight on common beans. Ann Rep Bean Improv Coop 43:72-73

Godoy-Lutz G, Steadman JR, Higgins R, Powers K (2003) Genetic variation among isolates of the web blight pathogen of common bean based on PCR-RFLP of the ITS-rDNA region. Plant Dis $87: 766-771$

Godoy-Lutz G, Kuninaga S, Steadman JR, Powers K (2008) Phylogenetic analysis of Rhizoctonia solani subgroups associated with web blight symptoms on common bean based on ITS5.8S rDNA. J Gen Plant Pathol 74:32-40

González-Vera AD, Bernardes-de-Assis J, Zala M, McDonald BA, Correa-Victoria F, Graterol-Matute EJ, Ceresini PC (2010) Divergence between sympatric rice and maize-infecting populations of Rhizoctonia solani AG 1 IA from Latin America. Phytopathology 100:172-182

Grosch R, Schneider JHM, Peth A, Waschke A, Franken P, Kofoet A, Jabaji-Hare SH (2007) Development of a specific PCR assay for the detection of Rhizoctonia solani AG 1-1B using SCAR primers. J Appl Microbiol 102:806-819

Grosch R, Schneider JHM, Kofoet A, Feller C (2011) Impact of continuous cropping of lettuce on the disease dynamics of bottom rot and genotypic diversity of Rhizoctonia solani AG 1-IB. J Phytopathol 159:35-44

Gupta M, Chyi Y-S, Romero-Severson J, Owen JL (1994) Amplification of DNA markers from evolutionary diverse genomes using single primers of simple sequence repeats. Theor Appl Genet 89:998-1006

Hammer $\varnothing$, Harper DAT, Ryan PD (2001) PAST: paleontological statistics software package for education and data analysis. Palaeontologia Electronica 4(1):9

Jaccard P (1901) Étude comparative de la distribution florale dans une portion des Alpes et des Jura. Bull Soc Vaudoise Sci Nat 37:547-579

Jana TK, Singh NK, Koundal KR, Sharma TR (2005) Genetic differentiation of charcoal rot pathogen, Macrophomina phaseolina, into specific groups using URP-PCR. Can J Microbiol 51:159-164 
Justesen AF, Yohalem D, Bay A, Nicolaisen M (2003) Genetic diversity in potato field populations of Thanatephorus cucumeris AG-3, revealed by ITS polymorphism and RAPD markers. Mycol Res 107:1323-1331

Kang H, Park DS, Go SJ, Eun MY (2002) Fingerprinting of diverse genomes using PCR with universal rice primers generated from repetitive sequence of Korean weedy rice. Mol Cells 13:281-287

Kiyosi T, Naito S, Ochi S, Akino S, Kondo N (2005) Analysis of genetic variation among subgroups of Rhizoctonia solani anastomosis group 2 (AG-2) by inter simple sequence repeat (ISSR)PCR. Ann Rep Soc Plant Prot North Japan 56:34-37

Klich MA, Mullaney EJ (2004) Molecular methods for identification of plant pathogenic fungi. In: Arora DK, Bridge PD, Bhatnagar D (eds) Fungal biotechnology in agricultural, food and environmental applications. Marcel Dekker, New York, pp 81-91

Kosman E, Leonard KJ (2005) Similarity coefficients for molecular markers in studies of genetic relationships between individuals for haploid, diploid, and polyploid species. Mol Ecol 14:415-424

Kuninaga S, Natsuaki T, Takeuchi T, Yokosawa R (1997) Sequence variation of the rDNA ITS regions within and between anastomosis groups in Rhizoctonia solani. Curr Genet 32:237-243

Longato S, Bonfante P (1997) Molecular identification of mycorrhizal fungi by direct amplification of microsatellite regions. Mycol Res 101:425-432

MacNish GC, Carling DE, Brainard KA (1997) Relationship of microscopic and macroscopic vegetative reactions in Rhizoctonia solani and the occurrence of vegetatively compatible populations (VCPs) in AG 8. Mycol Res 101:61-68

Masangano CM, Miles CA (2004) Factors influencing farmer's adoption of kalima bean (Phaseolus vulgaris L.) variety in Malawi. J Subs Agric 24:117-129

McDonald BA, Linde C (2002) Pathogen population genetics, evolutionary potential and durable resistance. Annu Rev Phytopathol 40:349-379

Meinhardt LW, Wulff NA, Bellato CM, Tsai SM (2002) Genetic analyses of Rhizoctonia solani isolates from Phaseolus vulgaris grown in the Atlantic Rainforest Region of São Paulo, Brazil. Fitopatol Bras 27:259-267

Muir G, Schlötterer C (1999) Limitations to the phylogenetic use of ITS sequences in closely related species and populationsa case study in Quercus petraea (Matt.) Liebl. In: Gillet EM (ed) Which DNA marker for which purpose? Final compendium of the research project: development, optimization and validation of molecular tools for assessment of biodiversity in forest trees. European Union DGXII Biotechnology FW IV Research Programme Molecular Tools for Biodiversity, Universität GöHingen, Institut für Forstgenetik und Forst pflanzenzüchtung, Universität GöHingen, p 7

Nei M, Li WH (1979) Mathematical models for studying genetic variation in terms of restriction endonucleases. Proc Natl Acad Sci USA 76:5269-5273

Nybom H (2004) Comparison of different nuclear DNA markers for estimating intraspecific genetic diversity in plants. Mol Ecol 13:1143-1155

Ogoshi A (1987) Ecology and pathogenicity of anastomosis and intraspecific groups of Rhizoctonia solani Kühn. Annu Rev Phytopathol 25:125-143

Peakall R, Smouse PE (2006) GenAlEx 6: genetic analysis in Excel. Population genetic software for teaching and research. Mol Ecol Notes 6:288-295
Peakall R, Smouse PE (2009) GenAlEx tutorials: introduction to population genetic analysis. Australian National University, Canberra

Rosewich UL, Pettway RE, McDonald BA, Kistler HC (1999) High levels of gene flow and heterozygote excess characterize Rhizoctonia solani AG 1-1A (Thanatephorus cucumeris) from Texas. Fungal Gen Biol 28:148-159

Sharma M, Gupta SK, Sharma TR (2005) Characterization of variability in Rhizoctonia solani by using morphological and molecular markers. J Phytopathol 153:449-456

Sharon M, Kuninaga S, Hyakumachi M, Sneh B (2006) The advancing identification and classification of Rhizoctonia spp. using molecular and biotechnological methods compared with the classical anastomosis grouping. Mycoscience 47:299-316

Singh SP, Schwartz HF (2010) Breeding common bean for resistance to diseases: a review. Crop Sci 50:2199-2223

Sneh B, Burpee L, Ogoshi A (1991) Identification of Rhizoctonia species. APS Press, St. Paul

Stodart BJ, Harvey PR, Neate SM, Melanson DL, Scott ES (2007) Genetic variation and pathogenicity of anastomosis group 2 isolates of Rhizoctonia solani in Australia. Mycol Res 111:891-900

Swofford DL (2003) PAUP*: phylogenetic analysis using parsimony (*and other methods), version 4. Sinauer, Sunderland

Thompson JD, Higgins DG, Gibson TJ (1994) Clustal W: improving the sensitivity of progressive multiple sequence alignment through sequence weighting, position-specific gap penalties and weight matrix choice. Nucleic Acids Res 22:4673-4680

Ureña-Padilla AR, MacKenzie SJ, Bowen BW, Legard DE (2002) Etiology and population genetics of Colletotrichum spp. causing crown and fruit rot of strawberry. Phytopathology 92:1245-1252

Vilgalys R, Cubeta MA (1994) Molecular systematics and population biology of Rhizoctonia. Annu Rev Phytopathol 32:135-155

White TJ, Bruns T, Lee S, Taylor J (1990) Amplification and direct sequencing of fungal ribosomal RNA genes for phylogenetics. In: Innis MA, Gelfand DH, Sninsky JJ, White TJ (eds) PCR protocols: a guide to methods and applications. Academic Press, San Diego, pp 315-322

Worrall JJ (1994) Population structure of Armillaria species in several forest types. Mycologia 86:401-407

Wortman CS (2006) Phaseolus vulgaris (common beans). In: Brink M, Belay G (eds) Plant resource of tropical Africa 1. Cereals and pulses. Backhuys, Wageningen, pp 146-151

Xu J (2006) Fundamentals of fungal molecular population genetic analyses. Curr Issues Mol Biol 8:75-90

Yang HA, Sivasithamparam K, O’Brien PA (1993) Mycelial interactions and the potential use of tuft formation in characterising Rhizoctonia solani isolates infecting cereals. Austral J Bot 41:253-262

Yang HA, Sivasithamparam K, Barton JE, O'Brien PA (1995) Characterization of cereal bare patch isolates of Rhizoctonia solani by random amplified polymorphic DNA analysis. Plant Pathol 44:811-818

Zala M, McDonald BA, Bernardes de Assis J, Ciampi MB, Storari M, Peyer P, Ceresini PC (2008) Highly polymorphic microsatellite loci in the rice- and maize-infecting fungal pathogen Rhizoctonia solani anastomosis group 1 IA. Mol Ecol Resour 8:686-689 